OPEN ACCESS

Edited by:

Carlo Pucillo,

University of Udine, Italy

Reviewed by:

Petr Draber,

Institute of Molecular Genetics

(ASCR), Czechia

Lubica Draberova,

Institute of Molecular Genetics

(ASCR), Czechia

Wahn Soo Choi,

Konkuk University, South Korea

${ }^{*}$ Correspondence:

Margarita Martin

martin_andorra@ub.edu

Specialty section:

This article was submitted to

Molecular Innate Immunity,

a section of the journal

Frontiers in Immunology

Received: 04 February 2019

Accepted: 25 April 2019

Published: 09 May 2019

Citation:

Navinés-Ferrer A, Ainsua-Enrich E,

Serrano-Candelas E, Sayós $J$ and

Martin M (2019) Myo1f, an Unconventional Long-Tailed Myosin, Is

a New Partner for the Adaptor 3BP2

Involved in Mast Cell Migration.

Front. Immunol. 10:1058

doi: 10.3389/fimmu.2019.01058

\section{Myo1f, an Unconventional Long-Tailed Myosin, Is a New Partner for the Adaptor 3BP2 Involved in Mast Cell Migration}

\author{
Arnau Navinés-Ferrer ${ }^{1,2}$, Erola Ainsua-Enrich ${ }^{1,2}$, Eva Serrano-Candelas ${ }^{1,2}$, Joan Sayós ${ }^{3}$ \\ and Margarita Martin ${ }^{1,2 *}$
}

${ }^{1}$ Biochemistry Unit, Biomedicine Department, Faculty of Medicine, University of Barcelona, Barcelona, Spain, ${ }^{2}$ Laboratory of Clinic and Experimental Immunoallergy, IDIBAPS, Barcelona, Spain, ${ }^{3}$ Immune Regulation and Immunotherapy Group, CIBBIM-Nanomedicine, Vall d'Hebron University Hospital, Research Institute (VHIR), Autonomous University of Barcelona, Barcelona, Spain

Mast cell chemotaxis is essential for cell recruitment to target tissues, where these cells play an important role in adaptive and innate immunity. Stem cell factor (SCF) is a major chemoattractant for mast cells. SCF binds to the KIT receptor, thereby triggering tyrosine phosphorylation in the cytoplasmic domain and resulting in docking sites for $\mathrm{SH} 2$ domain-containing molecules, such as Lyn and Fyn, and the subsequent activation of the small GTPases Rac that are responsible for cytoskeletal reorganization and mast cell migration. In previous works we have reported the role of 3BP2, an adaptor molecule, in mast cells. 3BP2 silencing reduces FcERI-dependent degranulation, by targeting Lyn and Syk phosphorylation, as well as SCF-dependent cell survival. This study examines its role in SCF-dependent migration and reveals that 3BP2 silencing in human mast cell line (LAD2) impairs cell migration due to SCF and IgE. In that context we found that 3BP2 silencing decreases Rac-2 and Cdc42 GTPase activity. Furthermore, we identified Myo1f, an unconventional type-I myosin, as a new partner for 3BP2. This protein, whose functions have been described as critical for neutrophil migration, remained elusive in mast cells. Myo1f is expressed in mast cells and colocalizes with cortical actin ring. Interestingly, Myo1f-3BP2 interaction is modulated by KIT signaling. Moreover, SCF dependent adhesion and migration through fibronectin is decreased after Myo1f silencing. Furthermore, Myo1f silencing leads to downregulation of $\beta 1$ and $\beta 7$ integrins on the mast cell membrane. Overall, Myo1f is a new 3BP2 ligand that connects the adaptor to actin cytoskeleton and both molecules are involved in SCF dependent mast cell migration.

Keywords: adaptor molecules, unconventional myosins, KIT signaling, mast cells, cell migration and adhesion, cytoske leton 


\section{INTRODUCTION}

Mast cell recruitment into connective tissue in a healthy or pathological situation requires cell adhesion, spreading and migration, and these events are transduced from external stimuli to cytoskeleton rearrangements. Most established mast cell chemoattractants are antigens recognized by immunoglobulins bound to FceRI and stem cell factor (SCF), the ligand for the KIT receptor, a type III tyrosine kinase receptor (1). KIT signal transduction is crucial for mast cell growth, survival and differentiation, as well as for the migration and homing of mast cells into target tissues. KIT through PI3 kinase signaling influences mast cell growth and survival (2). SCF is a major chemotactic attractant for mast cells and their precursors. Once bound to KIT, SCF causes KIT tyrosine phosphorylation and formation of docking sites for $\mathrm{SH} 2$ domain-containing molecules, such as Lyn and Fyn. Activation of Fyn leads to phosphorylation of Gab2 and subsequent activation of the small GTPase Rac that is responsible for the cytoskeletal reorganization and mast cell migration (3).

The SH3-binding protein 2 (3BP2) is a cytoplasmic adapter protein originally identified to bind to the tyrosine kinase Abl SH3 domain (4). Human 3BP2 is a 561-aa protein containing an N-terminal pleckstrin homology $(\mathrm{PH})$ domain, an SH3binding proline-rich region, and a C-terminal SH2 domain. 3BP2 positively regulates mast cell responses through FceRI and KIT receptors $(5,6)$. The knockdown expression of 3BP2 reduces degranulation, cytokine secretion and mast cell survival $(5,6)$. It has been reported that $3 \mathrm{BP} 2$ is required for optimal activation of Src family kinases and small GTPase Rac2 that regulates chemoattractant-mediated neutrophil activation, and motility. Consequently, the loss of 3BP2 increases susceptibility to infections such as Listeria monocytogenes. These functional defects are partially explained by the failure to fully activate Vav1 (7). Vav1 is a guanosine-nucleotide-exchange factor (GEF) for members of the Rho GTPase family (8). RhoA, Rac1,2,3, and Cdc42 belong to the family of Rho GTPases that regulates a range of biological response pathways, including cell motility and actin dynamics (9).

This work aims to investigate the role of 3BP2 in cytoskeleton reorganization and mast cell migration. In order to shed light on the molecules involved in 3BP2 signalosome, the three-hybrid screening system was performed on a bone marrow expression library using human 3BP2 as bait. Vav1 and Myolf were found to be ligand partners for 3BP2. Vav1 has previously been reported to bind to Y183 3BP2 (10), but Myolf represents a novel binding ligand for $3 \mathrm{BP} 2$ and its expression and function in mast cells remain elusive.

Myolf is a long-tailed unconventional class I myosin whose gene is located on the chromosome 19 (19p13.3-p13.2) (11). Myosins are actin-dependent molecular motors that use the energy from ATP hydrolysis to move along actin filaments (12). Class I myosins are evolutionarily ancient, represent the largest group of unconventional myosins and exist in a wide range of species. Mice and humans have a total of eight class I myosin heavy-chain genes, six of which encode short-tailed forms (Myola, b, c, d, g and h) and two of which encode long-tailed (amoeboid) forms (Myole and f). All class I myosins consist of an N-terminal motor domain, light-chain-binding IQ motifs (calmodulin binding) and a basic tail homology 1 (TH1) domain thought to affect interactions with membranes. Long-tailed class I myosins have an additional proline-rich TH2 domain and a TH3 domain containing a single Src homology 3 (SH3) domain (11). The Myolf transcript has been described as selectively expressed in the spleen, mesenteric lymph nodes, thymus, lung, NK cells, macrophages, and dendritic cells (13).

Interestingly, Myolf knockout mice have also been reported to show increased susceptibility to infection by Listeria monocytogenes as a consequence of abnormally increased adhesion and reduced motility of neutrophils. This increased adhesion results from augmented exocytosis of $\beta 2$ integrincontaining granules (14).

This study examines the capacity of 3BP2 to regulate Rho GTPase activity and mast cell migration and identifies Myolf as a binding partner for 3BP2. Further, it characterizes Myolf expression and distribution in mast cells and evaluates Myolf function in adhesion, integrin expression, and SCF dependent migration in mast cells.

\section{MATERIALS AND METHODS}

\section{Cell Lines and Reagents}

The LAD2 huMC line kindly provided by Drs. A. Kirshenbaum and D.D. Metcalfe (National Institutes of Health, Bethesda, MD) was grown in StemPro-34 media (Life Technologies, Carlsbad, CA), supplemented with StemPro-34 nutrient and L-glutamine $(2 \mathrm{mM})$, penicillin $(100 \mathrm{U} / \mathrm{mL})$ and streptomycin $(100 \mu \mathrm{g} / \mathrm{mL})$, and $100 \mathrm{ng} / \mathrm{mL}$ SCF (Amgen, Thousand Oaks, CA) (15). The human mast cell line HMC-1 was obtained from J.H. Butterfield (Mayo Clinic, Rochester, MN, USA) and was grown in Iscove's medium supplemented with $10 \%$ heat-inactivated FBS, penicillin $(100 \mathrm{U} / \mathrm{ml})$, and streptomycin $(100 \mu \mathrm{g} / \mathrm{ml})(16)$. COS-7 cell line was cultured in Dulbecco's Modified Eagle Medium (DMEM), $10 \%$ FCS, $1 \%$ penicillin-streptomicin (mixture 5k/5k), 1\% Lglutamine A $200 \mathrm{mM}$.

\section{Antibodies and Other Reagents}

Mouse antibodies, $\alpha$-3BP2 C5, $\alpha$-3BP2 C11, $\alpha$-Myolf C5, $\alpha$-KIT (clone Ab81), and rabbit $\alpha$-Kit (H300) were purchased from Santa Cruz (Santa Cruz Biotechnology, Inc. Santa Cruz, CA). Mouse anti-CD29-APC ( $\alpha$-integrin $\beta 1)$ clone MAR4 from BD Pharmigen (BD Biosciences, San José, CA), mouse $\alpha$-integrin $\beta 7-\mathrm{PE}$ from Biolegend (San Diego, CA), goat $\alpha$-mouse alexa647 , and goat $\alpha$-rabbit alexa-488 were from Life Technologies (Carlsbad, CA), mouse $\alpha$-human-FceRI-PE from eBioscience (San Diego, CA). Mouse $\alpha$-Rac1, $\alpha$-RhoA, and $\alpha$-Cdc42 antibodies were from Cytoskeleton (Cytoskeleton Inc., Denver, $\mathrm{CO})$, mouse $\alpha$-Rac2 antibody was from antibodies-online. Antiphosphotyrosine (pTyr) monoclonal was obtained from Zymed Laboratories (Invitrogen Life Technologies, Carlsbad, CA). Biotinylated human IgE (IgEB) was obtained from Abbiotec (San Diego, CA, USA). Anti-mouse peroxidase Ab was obtained from DAKO (Carpinteria, CA, USA). Streptavidin, 
the tyrosine kinase inhibitor sunitinib malate, puromycin, polylysine-D, fibronectin, doxycycline hyclate, mouse $\alpha$-tubulin (DM1A), and mouse $\alpha$-flag (m2Ab) were purchased from Sigma (Sigma-Aldrich, St. Louis, MO, USA). $\alpha$-pKIT Tyr703 was from Cell Signaling (Cell Signaling Technology, Danvers, MA) and $\alpha$-GPF from Roche (Roche Molecular Biochemical, Pleasanton, CA). Goat $\alpha$-rabbit-HRP was from Life Technologies (Life Technologies).

\section{Cell Activation or Inhibition}

Cells were starved overnight in culture media without SCF. The following day, cells were stimulated with $100 \mathrm{ng} / \mathrm{ml}$ of SCF in Tyrode's buffer for the indicated times. For IgEdependent activation we sensitized cells with biotinylated $\operatorname{IgE}$ $(0.1 \mu \mathrm{g} / \mathrm{ml})$ overnight, and stimulated them for $30 \mathrm{~min}$ at $37^{\circ} \mathrm{C}$ with streptavidin $(0.4 \mu \mathrm{g} / \mathrm{ml})$ to induce IgE crosslinking. For inhibition, cells were incubated with Sunitinib for $30 \mathrm{~min}$ at $37^{\circ} \mathrm{C}$ in Tyrode's Buffer, DMSO was used as a control.

\section{Immunofluorescence Assays}

Cells were activated or inhibited as described above. Afterwards, cells were fixed in PFA 4\%-phosphate buffered saline (PBS) at $4^{\circ} \mathrm{C}$. Then, cells were seeded on a poly-lysine-D coated plate with a Cytospin device (50.000 cells/sample). Cells were permeabilized with Saponin buffer (PBS-0.05\% Saponin) for $15 \mathrm{~min}$ at $4^{\circ} \mathrm{C}$. Afterwards, we used blocking buffer [0.2\% skimmed milk, $2 \%$ FCS, $1 \%$ bovine serum albumin (BSA), $0.01 \%$ triton X-100, $0.01 \%$ $\mathrm{NaN}_{3}, 20 \%$ Rabbit Serum (or 20\% FCS), dissolved in PBS] for $1 \mathrm{~h}$ at $4{ }^{\circ} \mathrm{C}$. We used primary antibodies $(0.1-0.2 \mu \mathrm{g} / 100.000$ cell $)$ for $2 \mathrm{~h}$ of incubation at $4^{\circ} \mathrm{C}$. At last, we used goat anti-mouse or goat anti-rabbit secondary antibodies labeled with Alexa-488 or Alexa-647 for $45 \mathrm{~min}$ (dilution 1:300 - 1:500) at $4^{\circ} \mathrm{C}$. For nuclei staining we used Hoechst stain (dilution 1:10.000 in PBS-0.1\% BSA), and for actin staining we used phalloidin-TRITC (dilution 1:500 - 1:1000). Preparations were visualized with a Leica SP5 confocal microscope. All images were processed with Fiji/ImageJ free software (17).

\section{Yeast Three-Hybrid Assay}

The yeast three-hybrid system was performed as described elsewhere (18). The 3BP2 adaptor cloned in the bicistronic pBridge vector (which carries the src-Fyn clone) and transformed in the yeast strain CG1945 was used as a bait to screen a human bone marrow matchmaker cDNA library cloned in pACT2 (Clontech Laboratories Inc, Mountain View, CA, USA). Cotransformed clones that grew under restrictive conditions were then tested using the $\beta$-galactosidase assay. The $\beta$ galactosidase liquid culture assay using o-nitrophenyl $\beta$-Dgalactopyranoside as a substrate was carried out as described in the Clontech yeast protocols handbook. Positive clones were processed to purify their plasmids and they were sequenced.

\section{Active GTPase Assays}

GTPase activation assays were performed using Rac1, Cdc42, and RhoA G-LISA kits following manufacturer's instructions (Cytoskeleton) as well as described elsewhere (19). Briefly, Cell lysates $\left(5 \times 10^{5}\right.$ to $2 \times 10^{6}$ cells $)$ were prepared using G-LISA lysis buffer, snap-frozen in liquid nitrogen and processed within 2 weeks after preparation. Lysate aliquots, corresponding to Rac1Rac2, Cdc42, and RhoA assays, were applied, respectively, to wells coated with Rac1, Cdc42, or Rho-GTP-binding protein. Active, GTP-bound GTPases bound to the wells were detected with the corresponding specific Ab. Constitutively active proteins were used as a standard.

\section{Immunoprecipitation, Immunoblotting, and COS Transfection}

Cells were treated with Sunitinib as described above. Whole cell lysate preparations were obtained as described elsewhere (20). Immunoprecipitation experiments were conducted using a procedure described elsewhere (5). COS-7 cells were transiently transfected using Nucleofector (Cell Line Nucleofector Kit V from Lonza Cologne AG, Lonza) following the manufacturer's instructions. Cells were transfected with a flag-tagged Myolf construct from (OriGene Technologies, Rockville, MD), cloned into a pCMV6-Entry plasmid. 3BP2 cloned in pCDNA 3.1 and Fyn cloned in psra used in COS transfections were described in Saborit et al. (21) and Alvarez-Errico et al. (22), respectively. $\mathrm{SH} 2-3 \mathrm{BP} 2-\mathrm{GFP}$ construct was obtained cloning the $\mathrm{SH} 2$ domain of 3BP2 into a pN3-EGFP construct (Clontech Laboratories, Inc, Mountain View, CA, USA); pN3-EGFP plasmid was used as control.

\section{Lentiviral Transduction}

Lentiviral particles to silence the $3 \mathrm{BP} 2$ gene expression were generated using Mission shRNA technology, according to the manufacturer's instructions (Sigma-Aldrich, St. Louis, MO) as described elsewhere $(5,6)$. The lentivirus with shRNA sequences A, B, C, or D for Myolf were from Origen Technologies. The TRCN0000158118 sequence that overlaps with sequence D in the Origen plasmids (CGTCTTCAAGACCGAGTTTGT) was furthered cloned into a Tet-pLKO-puro plasmid [Addgene plasmid 21915; (23)] which expression is inducible by doxycycline $(0.5 \mu \mathrm{g} / \mathrm{mL})$ and used for subsequent experiments.

The Lenti ORF clone of human SH3-domain binding protein 2 (SH3BP2), transcript variant 1, mGFP tagged and Lenti vector with C-terminal monomeric GFP tag as a control (OriGene Technologies) were used for 3BP2 overexpression experiments.

\section{Migration Assays}

Migration assays were performed using transwell polycarbonate membranes from Costar $(8 \mu \mathrm{m}$ pores, Corning Incorporated, Kennebunk, ME) suitable for mast cells as reported in Kataoka et al. (24). Briefly, LAD2 cells were starved $\mathrm{O} / \mathrm{N}$ in complete media without SCF and, when necessary, with biotinylated IgE. The next day, $1 \times 10^{5}$ cells per point were washed with fresh StemPro-34 media and dropped into the upper transwells. After $10 \mathrm{~min}$ for stabilization we added the stimulus on the bottom well $(100 \mathrm{ng} / \mathrm{mL}$ of SCF, $0.4 \mu \mathrm{g} / \mathrm{ml}$ streptavidin or StemPro Supplement $1 \mathrm{x}$ ), and the cells were left to migrate for $4 \mathrm{~h}$ at $37^{\circ} \mathrm{C}$ and $5 \% \mathrm{CO}_{2}$. After $4 \mathrm{~h}$ the cells were rinsed with an EDTA-NaClPBS buffer to detach them from the bottom of the upper chamber, they were stained with crystal violet and counted under optic 
microscopy. In all cases, the cells in the upper chamber were counted after $4 \mathrm{~h}$ with Trypan blue to evaluate viability.

\section{Adhesion Assays}

P96 plates were coated $\mathrm{O} / \mathrm{N}$ with fibronectin $(20 \mu \mathrm{g} / \mathrm{mL})$, polylysine-D $(0.1 \% \mathrm{w} / \mathrm{v})$ or PBS. Next day, wells were washed with PBS, blocked with 5\% BSA and washed again with PBS. 1-5 $\times 10^{4}$ cells starved $\mathrm{O} / \mathrm{N}$ were dropped in triplicate wells and activated with $100 \mathrm{ng} / \mathrm{mL}$ SCF in complement-free StemPro-34 media for $30 \mathrm{~min}$. After that, wells were rinsed 3 times with PBS and the number of remaining cells was assessed with CellTiterGlo ${ }^{\circledR}$ Luminescent Cell Viability Assay from Promega (Promega Corporation, Madison, WI).

\section{FACS Staining}

$\beta 7$ and $\beta 1$ integrins, KIT and FceRI expression were detected by direct staining with the indicated Abs for $30 \mathrm{~min}$ at $4^{\circ} \mathrm{C}$. Cells were then analyzed using a FACSCalibur flow cytometer (FACScan; BD Biosciences). In all cases dead cells were excluded based on their Forward (FSC) and side scattering (SSC) profile.

\section{Data Analysis}

All results are expressed as mean \pm standard error of the mean (SEM). Unpaired student's $t$-test or one-way ANOVA were used to determine significant differences ( $p$-value) between two or several experimental groups, respectively, after determination of normal distribution of the sample and variance analysis.

\section{RESULTS}

\section{BP2 Is Critical for SCF-Dependent Mast Cell Migration}

Given that 3BP2 is required for proper KIT signaling (6), and SCF, the ligand for KIT, is a major chemotactic factor in mast cells (1), this study explores the capacity of 3BP2 to modulate SCF-dependent chemokinesis. Migration assays were carried out using Transwell chambers, with SCF as the stimuli. 3BP2 shRNAs sequences were validated in previous works $(5,6)$. Our data show that 3BP2-silenced LAD2 cells (Figure 1A) do not migrate toward an SCF gradient (Figure 1B). As described previously, 3BP2 knockdown cells downregulate KIT expression, thereby leading to cell apoptosis (6). The migration experiments were performed under the same conditions in which cell survival and KIT expression were not significantly affected (first week of transduction). The viability was tested in all these conditions to rule out a lack of migration due to cell apoptosis (data not shown). To ensure the specificity of this event, silenced cells were reconstituted for 3BP2 using a plasmid-encoding 3BP2-GFP protein or a control GFP protein (Figure 1C). The GFP and KIT expression levels were monitored to ensure good transfection efficiency before the migration tests were carried out (Figure 1D). As expected, 3BP2 reconstitution reestablished the capacity for cell migration (Figure 1E).

Next, we analyzed whether 3BP2 was also needed for mutant KIT D816V-mediated migration. KIT D816V is a hallmark of mastocytosis, a rare disease caused by the accumulation of functionally defective mast cells. For that we used HMC-1 cell line in which KIT has the gain-of-function mutation D816V. As shown in Figure 2, 3BP2 silencing impairs cell migration toward SCF in HMC-1 cells. In this case migration basal levels are higher than those observed in LAD2 mast cells since KIT signaling is constitutively active. Although the mutation confers receptor activation in absence of SCF, SCF addition still increases cell activation as reported by us and others $(6,25)$. Altogether our data indicates that $3 \mathrm{BP} 2$ provides signals needed for SCFdependent mast cell migration.

\section{BP2 Is Essential for FceRI-Mediated Mast Cell Migration}

It has been reported that Lyn and Syk are essential for FceRImediated migration (26). Since the adaptor molecule 3BP2 coprecipitates with Lyn and Syk in mast cells and 3BP2 silencing leads to a decrease in Syk phosphorylation (5) we next assessed the ability of $3 \mathrm{BP} 2$ to promote FceRI-mediated migration. For that purpose non target or 3BP2 silenced LAD2 cells were sensitized with biotinylated IgE overnight. Migration assays were performed using streptavidin as stimuli (mimicking the allergen). As shown in Figure 3, 3BP2 silencing leads to an impairment in migration toward the streptavidin. Levels of $F c \varepsilon R I$ in both types of cells were similar. As reported previously, 3BP2 silencing does not affect FceRI expression levels (5). To check whether 3BP2 role in chemotaxis goes beyond FcERI or KIT receptors we carried out migration assays using the StemPro 34 supplement as stimuli. This supplement contains a wide array of growth factors needed for growth and proliferation of LAD2 cells. Interestingly, cells where $3 \mathrm{BP} 2$ was silenced show less migration toward the stimuli suggesting an overall role of 3BP2 in LAD2 migration (Figure S1).

\section{The 3BP2 Adaptor Protein Is Required for Rac2 and Cdc42 Activation in Mast Cells}

The adaptor molecule 3BP2 has been proposed as a key molecule for Rho family GTPase activation and migration in neutrophils (7). The Rho family of GTPases undergoes activation by GTP/GDP exchange and controls cytoskeletal rearrangements (9). First we characterized the activation pattern of the Rho GTPase family in the human mast cell line LAD2 (Figure S2). Activation of Rac1, Rac2, and Cdc42 increases after IgE and SCF stimulation. Thus, we then performed an assay to determine RhoA/Rac1/Rac2/Cdc42 activity in 3BP2-silenced LAD2. Our results show that $\mathrm{Cdc} 42$ and Rac2 activation was significantly impaired in 3BP2-silenced cells after activation. Interestingly, Rac-1 was not modified, thus indicating that $3 \mathrm{BP} 2$ is selectively relevant for activation of some members of Rho family GTPases (Figure 4). The data suggest the involvement of 3BP2 in pathways associated with cell motility and actin dynamics.

\section{Myo1f as a Novel Ligand for 3BP2}

In parallel to these studies, we screened a human bone marrow library using the yeast three-hybrid system used previously (18, 21 ), this time with $3 \mathrm{BP} 2$ as the bait in order to search for new ligands for 3BP2. Our screening process rendered known partners for 3BP2, including Vav1 (data not shown) and Myolf, a novel ligand. Myolf is a long-tailed class I myosin that consists 


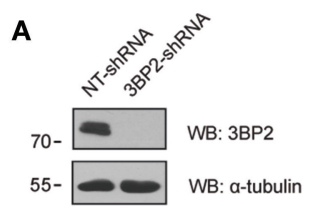

C

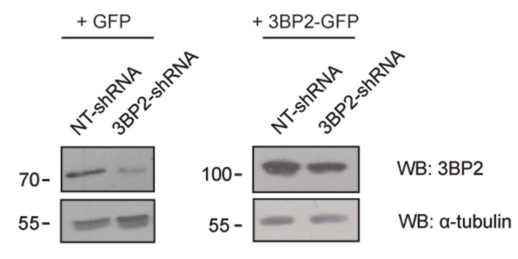

E

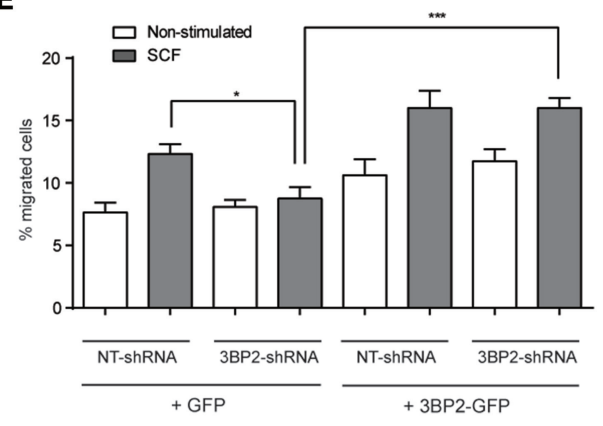

B

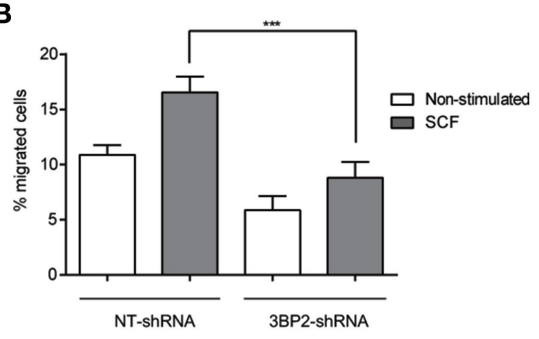

D
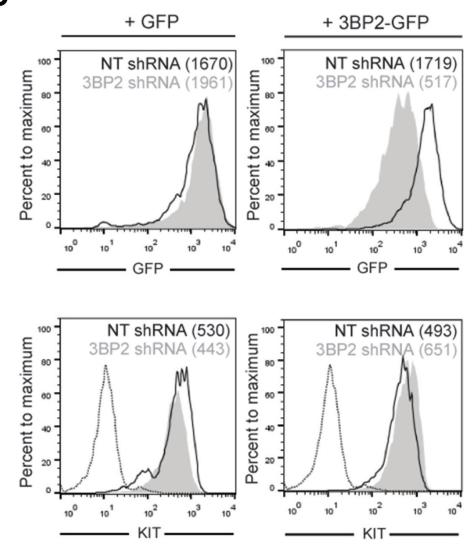

FIGURE 1 | 3BP2 knockdown impairs SCF-dependent mast cell migration. (A) Western blot showing the 3BP2 shRNA knockdown in LAD2 cells. (B) Percentage of migrated non-target control (NT-shRNA) o 3BP2-knockdown (3BP2-shRNA) LAD2 mast cells toward SCF gradient (100 ng/mL). (C) Western blot determination of the reconstitution of both groups with 3BP2-GFP or GFP alone. (D) GFP and KIT receptor expression determined by flow cytometry. NT-shRNA is represented by an empty black curve and 3BP2-shRNA is represented by a filled gray curve. Mean intensity of fluorescence (MIF) of each group is represented in parentheses. (E) Percentage of cell migration after $4 \mathrm{~h}$ chemotaxis with SCF $(100 \mathrm{ng} / \mathrm{mL})$ of silenced and reconstituted cells, as indicated in the figure. Viability was tested in the upper wells after the assay. The one-way ANOVA test was used for the statistical analysis $\left({ }^{*} p<0.05,{ }^{* \star *} p<0.001\right)$. Migration data are the mean of three independent experiments.

A

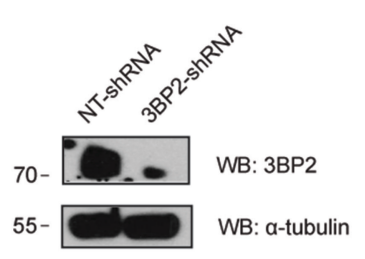

B

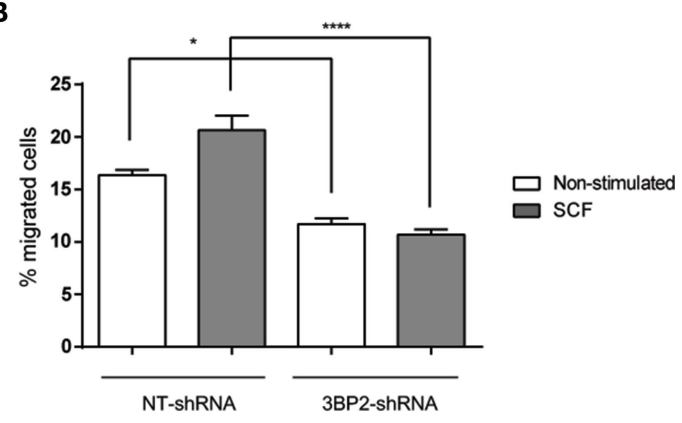

FIGURE 2 | 3BP2 knockdown decreases migration of mast cells harboring the KITD816V mutation. (A) Western blot showing the 3BP2 shRNAs knockdown in HMC-1 cells. (B) Percentage of migrated HMC-1 mast cells silenced for 3BP2 (3BP2-shRNA) or non-target control (NT-shRNA) toward an SCF gradient $(100 \mathrm{ng} / \mathrm{mL})$. The student's $t$-test was used for the statistical analysis $\left({ }^{\star} p<0.05,{ }^{\star \star \star \star} p<0.0001\right)$. In all migration assays, viability was tested in the upper wells after the assay. Data are the mean of three independent experiments.

of an N-terminal motor domain, light-chain-binding IQ motifs, a basic tail homology 1, a proline-rich TH2 domain and a TH3 domain containing a single Src homology 3 (SH3) domain. A positive clone observed in the screening process encoded the c-terminal region of the protein containing the complete $\mathrm{SH} 3$ domain (Figure 5A). Moreover, 3BP2 coprecipitated with Myo1f in transfected COS cells in the absence or presence of Fyn kinase (Figure 5B), thereby indicating an interaction that is 

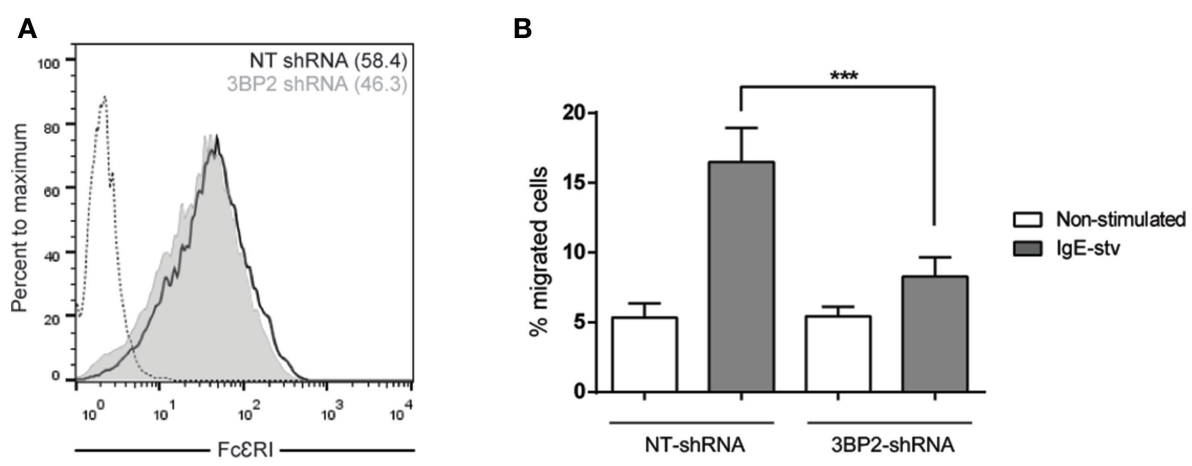

FIGURE 3 | 3BP2 also reduces significantly IgE-dependent cell migration. (A) FceRI expression in NT and 3BP2-silenced LAD2 cells. (B) Percentage of cell migration after $4 \mathrm{~h}$ chemotaxis with IgE + Streptavidin in NT and 3BP2-silenced cells. Viability was tested in the upper wells after the assay. The one-way ANOVA test was used for the statistical analysis ( $\left.{ }^{\star \star} p<0.001\right)$. Migration data are the mean of three independent experiments.

A

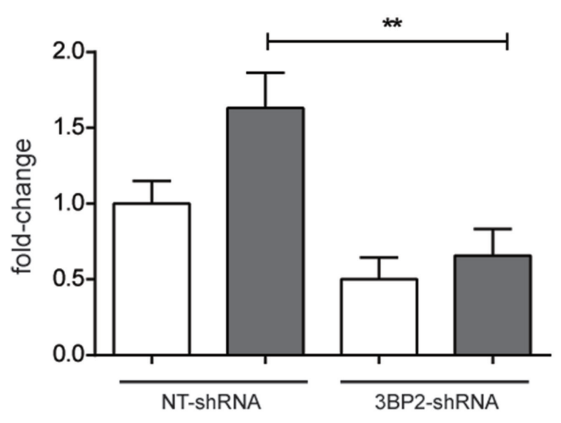

C

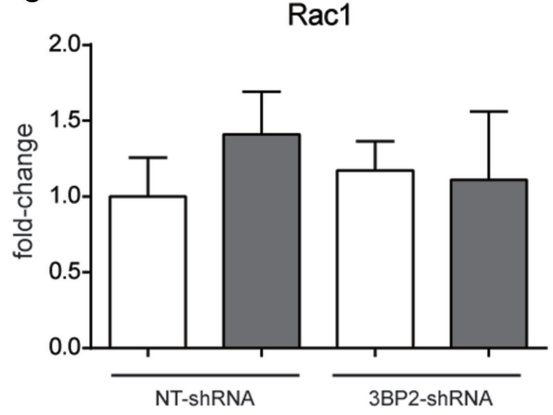

E

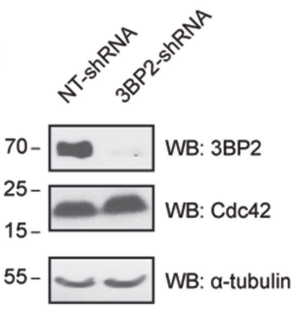

B

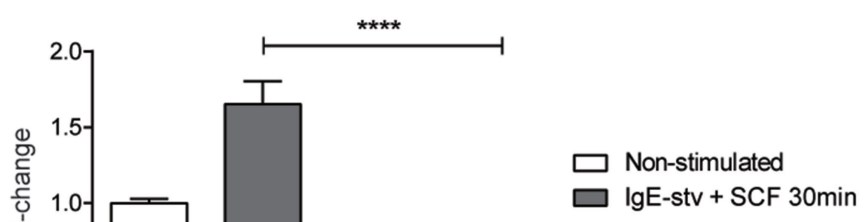

D
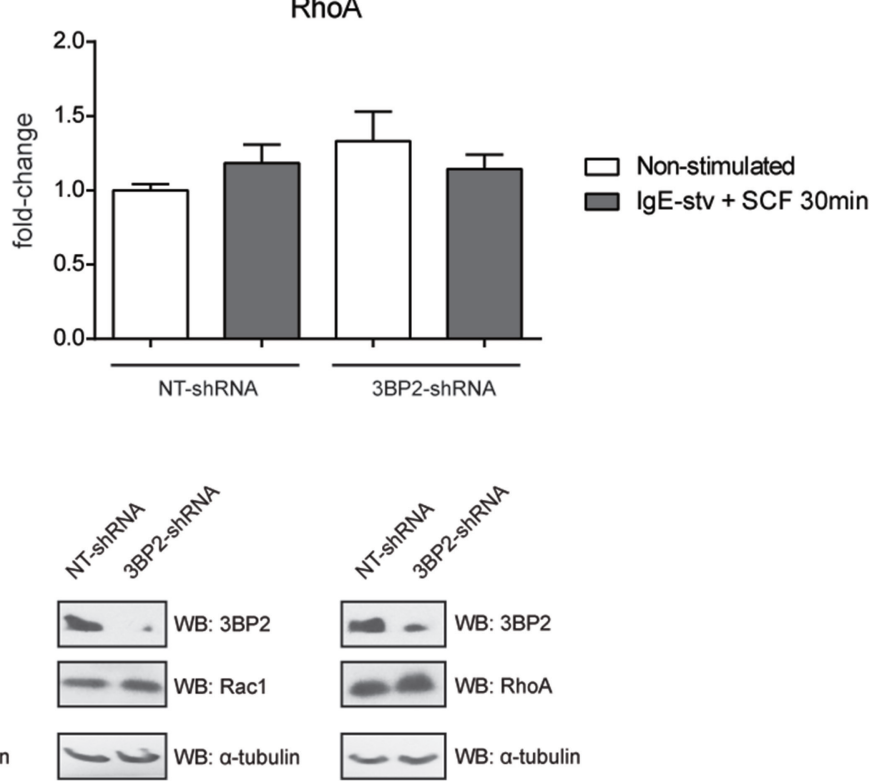

FIGURE 4 | 3BP2 knockdown impairs Cdc42 and Rac2 activation in mast cells. G-Lisa quantification of GTP-bound (active) small GTPases Rho (A) Cdc42; (B) Rac2, (C) Rac1, and (D) RhoA were performed before and after activation by IgE-stv plus SCF for $30 \mathrm{~min}$ in LAD2 cells. (E) Western blot showing GTPases levels in NT and 3BP2-silenced cells. The one-way ANOVA test was used for the statistical analysis $\left({ }^{* *} p<0.01,{ }^{* \star *} p<0.0001\right)$. Data are the mean of three independent experiments. 
independent of phosphorylation. Interestingly, Myolf and 3BP2 are susceptible to phosphorylation by Fyn kinase, thus suggesting regulation of these proteins upon phosphorylation. In order to check whether Myolf can also be recruited by the $\mathrm{SH} 2$ domain of 3BP2, we performed an immunoprecipitation experiment in COS cells transfected with only the SH2 domain of 3BP2 in the presence of Fyn. Our findings revealed that no binding was observed in these conditions (Figure 5C).

\section{Myo1f Is Expressed in Mast Cells and Colocalizes With 3BP2}

Next, we determined the expression of Myolf in human mast cells. Mast cell lines LAD2 and HMC-1 and CD34 ${ }^{+}$-derived human mast cells express Myolf, as confirmed by western blot in our study (Figure 6A). Myolf colocalizes with the cortical actin network in resting conditions and after SCF stimulation in LAD2 cells (Figure 6B). Myolf and 3BP2 showed some localization under resting and SCF-activated conditions. Interestingly, Myolf and 3BP2 colocalization was found mostly on the cell membrane at $5 \mathrm{~min}$ (Figure 6C). Our data suggest that KIT activation may modulate the 3BP2-Myolf interaction. In that context, in HMC1 cell line, where KIT is constitutively active, 3BP2 and Myolf colocalized at the plasma membrane. Remarkably, the KIT kinase inhibition with sunitinib altered the colocalization (Figure 6D) and 3BP2-Myolf coprecipitation is abrogated in those conditions (Figure 6E). These data indicate that KIT signaling can regulate the Myo1f-3BP2 interaction.

\section{Myo1f Knockdown Does Not Impair SCF-Dependent Mast Cell Migration}

We next assessed whether Myo1f knockdown can modulate KIT functions by analyzing cell migration. Various Myolf shRNA sequences were tested in LAD2 cells (Figure 7A). Only one shRNA sequence showed significant Myolf silencing and was further cloned under doxycycline-inducible plasmid to control Myolf silencing and reconstitution at will. Western blot was performed to corroborate the knockdown data (Figure 7B), and KIT expression levels were evaluated by flow cytometry in nontarget cells vs. Myo1f-silenced cells (Figure 7C). Our results show that Myolf knockdown does not affect the capacity of mast cells to migrate toward SCF under these conditions (Figure 7D). Viability was also monitored after migration and showed no changes (data not shown).

\section{$\beta 1$ (CD29) and $\beta 7$ Integrin Expression Are Affected in Myo1f and 3BP2 Silencing}

It has been reported that neutrophils from Myolf-deficient mice exhibit abnormally increased adhesion and reduced motility as a result of augmented exocytosis of $\beta 2$-integrin-containing granules and a reduction in cortical actin (14). $\beta 1$ and $\beta 7$ integrins are responsible for migration and homing in SCF-dependent mast cell migration (27). Thus, we analyzed the integrin profile of $\beta 1$ (CD29), $\beta 2$ (CD18), and $\beta 7$ chains in Myo1f vs. control cells. $\beta 2$ expression was very low in mast cells under various treatments, and no differences were observed in silenced or control cells (data not shown). Conversely, $\beta 1$ and $\beta 7$ integrins were well expressed in mast cells, and no significant differences were observed between untreated and SCF-stimulated cells in terms of membrane expression measured by flow cytometry (data not shown). Interestingly, Myolf-silenced cells were found to express significantly less $\beta 1$ integrin, in comparison with non-target cells (Figure 8A). Our results also show mild but significant differences in $\beta 7$ expression between control cells and Myo1f-silenced cells (Figure 8B).

SCF-dependent mast cell migration is preceded by an increase in cell adhesion, a process that is dependent on integrins (28). Next we assessed whether the differential expression of integrins on Myolf silencing affects SCF-dependent cell adhesion. As shown in Figure 8C, Myolf silencing induced by doxycycline affected SCF-induced adhesion to fibronectin.

Finally, we measured the capacity of these cells to migrate toward an SCF chemotactic gradient through a fibronectincoated surface. Our data show that Myolf-silenced cells had a significantly lower migration capacity under these conditions, thus indicating that this impaired adhesion affected mast cell migration (Figure 8D).

We conducted similar experiments in 3BP2 silencing cells assessing integrins expression profile. We found that $\beta 1$ integrin expression was significantly reduced but $\beta 7$ integrin expression was unaffected in 3BP2-silenced cells (Figures 9A,B). We found as well significant differences in cell adhesion to fibronectin in 3BP2-silenced cells (Figure 9C). These differences may also contribute to the capability of cells to migrate. As we show above when 3BP2 expression is low or almost absent cell migration is more grossly affected that the one observed in Myo1f-silenced cells.

\section{DISCUSSION}

Migration of mast cells is required for their recruitment to target tissues and for their infiltration to inflammation sites associated with chronic atopic diseases, or during bacterial or parasitic infection. Thus, mast cells recognize chemotactic stimuli and trigger a signaling cascade of events that lead to integrin activation, adhesion and migration. SCF, the KIT ligand, is a key chemotactic factor and is crucial for mast cell proliferation, survival, homing and migration. Proper KIT signaling is required to ensure that these events progress properly. Some years ago, our group showed that the 3BP2 adaptor protein previously described as critical for mast cell degranulation through FceRI (5) also regulates survival through KIT receptor expression and signaling (6). As we reported, 3BP2 regulates KIT transcription through microphthalmia-associated transcription factor (MITF), described to control KIT expression. Thus, reduced 3BP2 expression is associated with decreased KIT expression and increased cellular apoptosis (6).

In this study we show that 3BP2 also plays a role in SCFdependent cell migration. Since the silencing of 3BP2 ends up reducing KIT expression and compromising cell viability, all experiments we performed were monitored for KIT expression and cell viability. The mechanisms underlying 3BP2-modulated cell migration may be related to its role as a scaffold protein, 
A

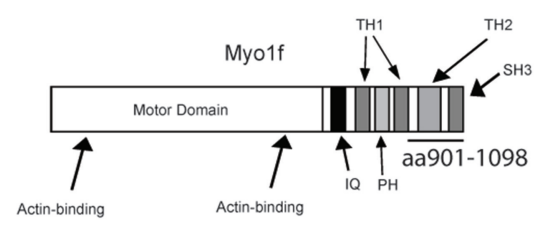

C

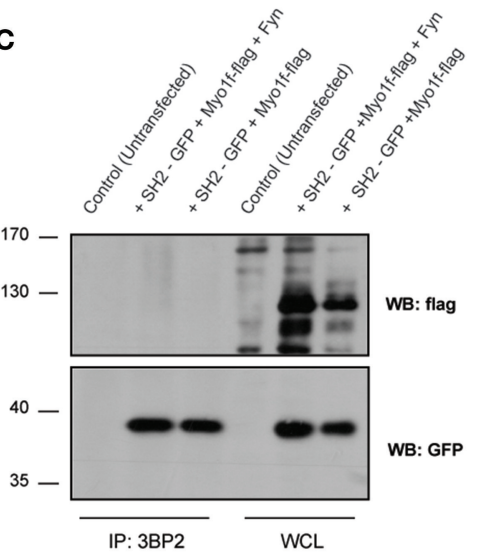

B

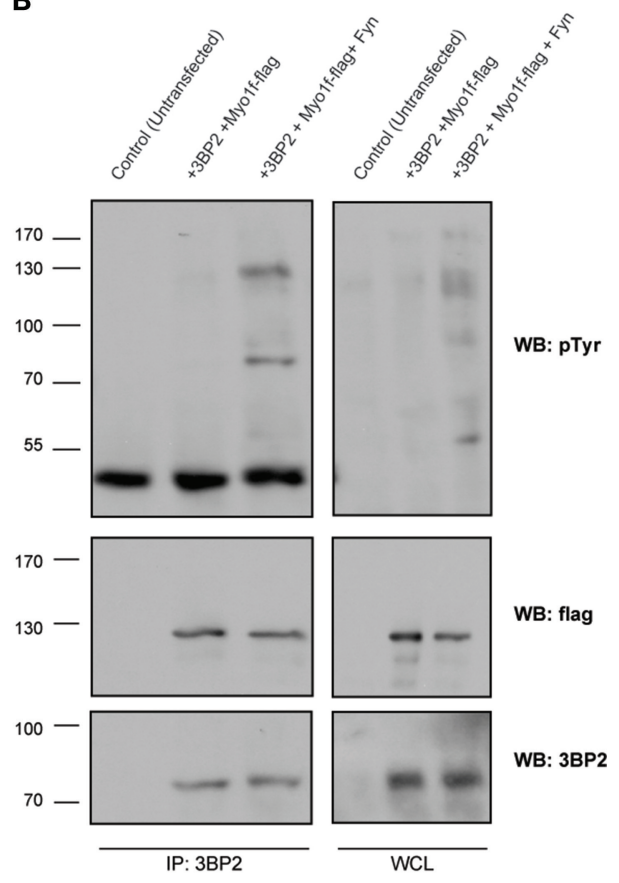

FIGURE 5 | Myo1f, a new ligand for 3BP2. (A) Representation of Myo1f. The clone identified through the three-hybrid assay was the SH3 region of this protein (aa901-1098). (B) Immunoprecipitation of the 3BP2 protein in COS-7 cells transfected with 3BP2 and Myo1f-flag, with or without the presence of Fyn kinase. Membrane was blotted with $\alpha$-pTyr, $\alpha$-flag, and $\alpha$-3BP2 antibodies. (C) Immunoprecipitation of 3BP2 in COS-7 cells transfected with the SH2 domain of 3BP2 (SH2-GFP) and Myo1f-flag, with or without the presence of Fyn kinase. Membrane was blotted with $\alpha$-flag and $\alpha$-GFP antibodies.

since with its binding partners it builds a molecular network that contributes to the KIT signalosome. Indeed, the silencing of 3BP2 reduces $\mathrm{PI} 3 \mathrm{~K}$ and MAP kinase signaling after SCF engagement (6). This work used the yeast three-hybrid system to screen a human bone marrow library, using human 3BP2 as bait, and identified Vav1 (clone encoding the SH2 domain; amino acids 665-754) and Myolf (clone encoding SH3 domain; amino acids 901-1185) as ligands for 3BP2. Vav1 has been reported to bind to 3BP2 in a phosphorylation-dependent manner, thus increasing NK cell killing $(10,21,29)$ and B cell activation (30). 3BP2 has been reported as crucial for full activation of Vav1 in neutrophils, thereby supporting a role for the adaptor in neutrophil activation and migration through activation of Rho family of GTPases (7). Rho GTPases, specifically Rac1,2,3, RhoA and Cdc42, have been shown to regulate various exocytosis-related events, including actin remodeling, exocytic complex formation and calcium influx, across a number of cell models (31). Although their exact mechanism of regulation may vary between cells, it appears that Rho GTPases are predominantly responsible for regulating actin remodeling. Racl and $\mathrm{Cdc} 42$ have been reported to stimulate mast cell exocytosis, while RhoA has no effect (32). Although Rac1 and Rac2 are 92\% identical, they have been shown to have distinct cellular functions (33). Therefore, a lack of Rac2 results in diminished chemotaxis and degranulation in mast cells, thus defining distinct functions for Rac2 that cannot be compensated for by $\operatorname{Rac1}(34,35)$. This is consistent with previous data where we reported that 3BP2 silencing expression inhibits mast cell degranulation (5) and with the present data, which showed that Rac2 and Cdc42 activation was impaired in 3BP2 knockdown mast cells in which chemotaxis was diminished. Interestingly, Rac2 knockout exhibits a reduction in mast cell survival (34) as occurs in 3BP2 silenced cells (6), thus suggesting that both molecules are involved in a common signal pathway.

The mechanism used for $3 \mathrm{BP} 2$ to connect KIT triggering with small GTPase activity has not been elucidated. 3BP2 is known to coprecipitate with KIT in mast cells but no direct binding to the receptor has been reported (6). Src kinases Lyn, Fyn and PI3K are ligands for KIT binding to Y568, Y570, and Y721, respectively, in the cytoplasmic tail of the human receptor. On the other hand, 3BP2 can be phosphorylated by Fyn and Lyn $(30,36)$ and has been reported to be associated with Src kinases $(5,36)$ and PI3K (29). It is therefore conceivable that KIT and 3BP2 are linked through these common partners. Interestingly, Fyn-dependent axis on KIT activation leads to the phosphorylation of Gab2 and cytoskeleton reorganization and mast cell migration through Rac GTPase activation (37-40). Studies with different murine KIT mutants showed the importance of Y567 and Y719 for KITmediated chemotaxis. Phosphorylated Y567 recruits Src kinases Lyn or Fyn, and this results in activation of the p38 pathway, which is also important for chemotaxis $(39,41)$. Interestingly, 3BP2 silencing impairs the p38 pathway in mast cells after FceRI triggering (5). Altogether, 3BP2 could act synergistically with Scr kinases, thus increasing the Rho family of small GTPases and chemotaxis. In contrast, phosphorylated Y179 recruits PI3K 


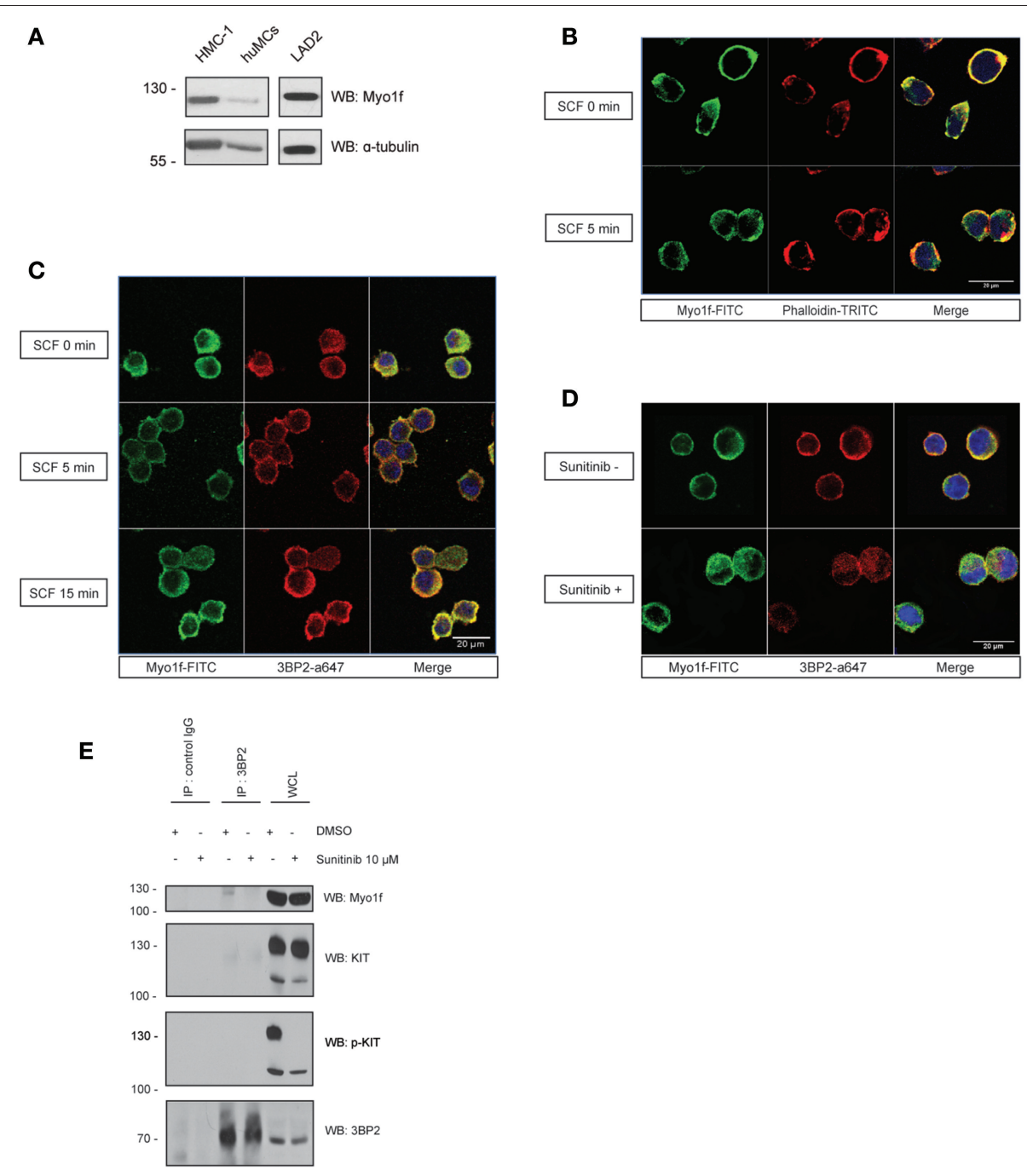

FIGURE 6 | 3BP2 and Myo1f colocalization is modulated by KIT signaling in mast cells. (A) Expression of Myo1f in the mast cell lines HMC-1 and LAD2 and in CD34+-derived human mast cells (huMCs). (B) Immunofluorescence of LAD2 mast cells showing Myo1f (green), actin staining (phalloidin; red) and the nucleus (Hoechst; blue) after $5 \mathrm{~min}$ of stimulation with SCF (100 ng/mL) or resting (0 min). (C) Immunofluorescence of LAD2 mast cells showing Myo1f (green), 3BP2 (red) and the nucleus (Hoechst; blue) after stimulation for different times with SCF (100 ng/mL) or resting (0 min). (D) Immunofluorescence of HMC-1 cells treated with sunitinib $(10 \mu \mathrm{M})$ or untreated showing Myo1f (green), 3BP2 (red) and the nucleus (Hoechst; blue). (E) Immunoprecipitation of 3BP2 in HMC-1 cells treated with sunitinib $(10 \mu \mathrm{M})$ or control (DMSO). Membrane was blotted with $\alpha$-Myo1f, $\alpha-3 B P 2$, and $\alpha-\mathrm{KIT} / \alpha-\mathrm{pKIT}$ antibodies to check KIT inhibition by sunitinib.

and the mediated and enhanced calcium signaling that has been found to be critical for chemotaxis (41). 3BP2 silencing has been reported to impair calcium signaling in mast cells (5). In summary, 3BP2, through common ligands, may modulate SCFdependent MAP kinase activity and calcium influx that leads to activity of the Rho family of small GTPases, which is important for mast cell chemotaxis.

In this work, we identified Myolf as a novel binding partner for 3BP2. Myolf is an unconventional long-tailed myosin not involved in muscle contraction and whose expression is restricted to the immune system. However, its expression and role in mast cell function remains unclear. We showed that Myo1f is expressed in CD34-derived mast cells and mast cell lines, and colocalizes with the cortical actin ring. 3BP2-Myolf interaction is independent of phosphorylation and possibly involves the SH3 domain of Myolf and the proline-rich domain of 3BP2. However, it may be modulated after KIT activation. After $5 \mathrm{~min}$ of SCF stimulation, 3BP2 translocates to the membrane, thereby increasing its colocalization with Myolf in that area. Myolf membrane location is also more apparent after KIT engagement. This is consistent with an increase in PI3K activity upon KIT activation and production of phosphatidylinositol-3, 4, 5-triphosphate (PIP3), a binding site for $\mathrm{PH}$-domain containing proteins like 3BP2 and Myolf. In the HMC-1 mast cell line (harboring KITD816V), where KIT is constitutively active, colocalization of both proteins can be observed in the membrane area and by coprecipitation. Interestingly, coprecipitation is abolished in 


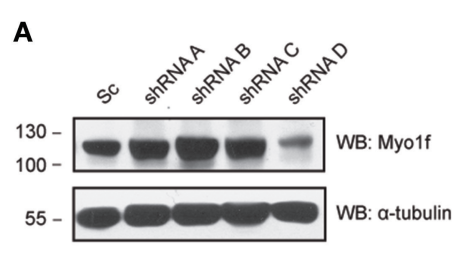

C

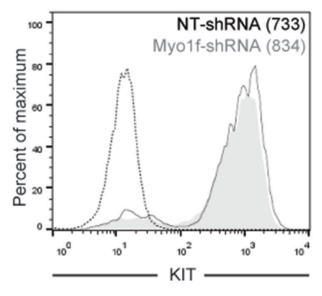

B

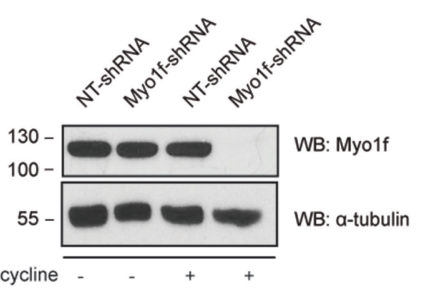

D

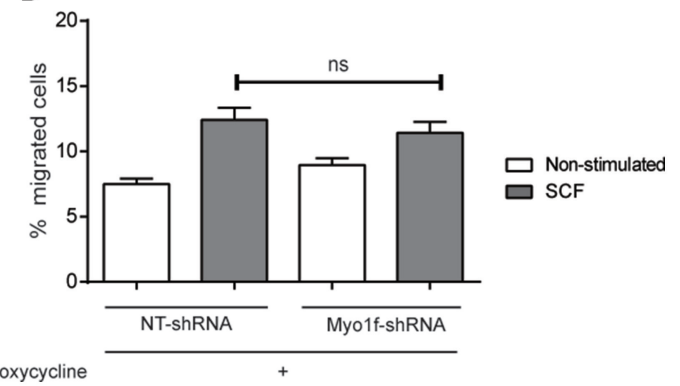

FIGURE 7 | Myo1f knockdown does not affect SCF-dependent migration. (A) Western blot showing the Myo1f shRNAs tested. (B) Western blot showing Myo1f knockdown and (C) membrane surface expression of KIT receptor in LAD2 mast cells silenced for Myo1f (Myo1f-shRNA) or non-target control (NT-shRNA) after doxycycline induction $(0.5 \mu \mathrm{g} / \mathrm{mL}$ ). (D) Percentage of migrated LAD2 mast cells silenced for Myo1f (Myo1f-shRNA) or non-target control (NT-shRNA) toward an SCF gradient $(100 \mathrm{ng} / \mathrm{mL})$ with doxycycline induction $(0.5 \mu \mathrm{g} / \mathrm{mL})$. The student's $t$-test was used for the statistical analysis. In all migration assays, viability was tested in the upper wells after the assay. Data are the mean of three independent experiments.

A

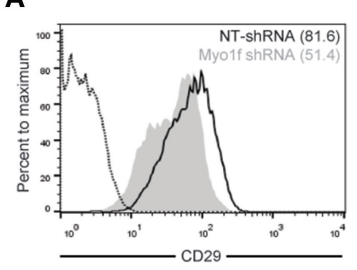

C
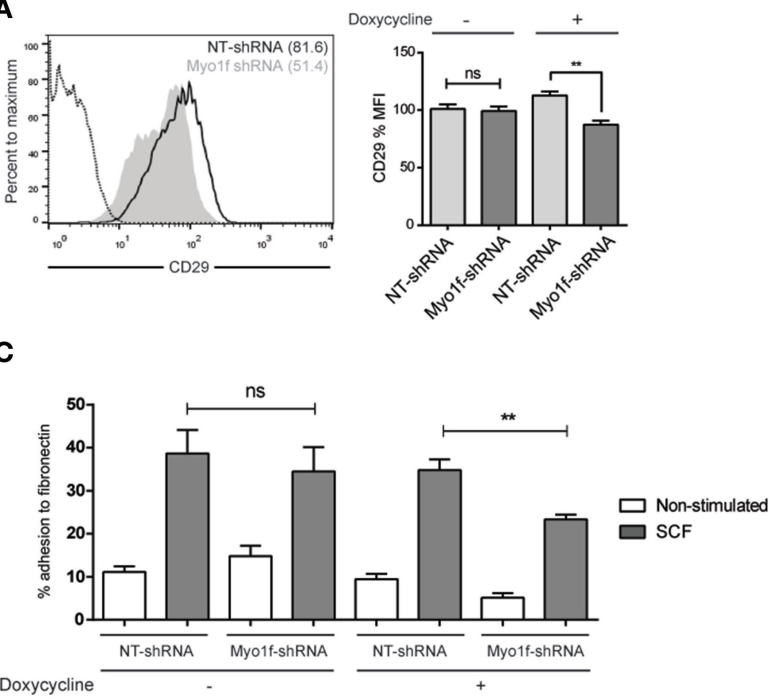

B
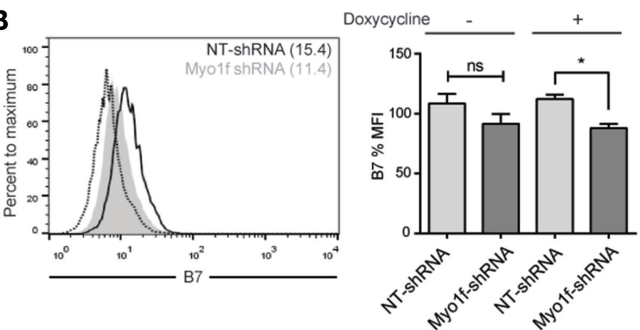

D

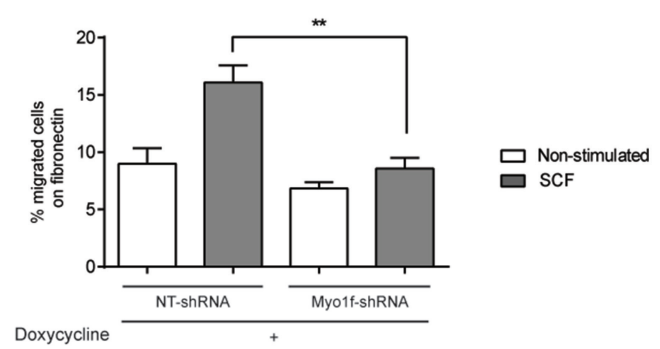

FIGURE 8 | $\beta 1$ and $\beta 7$ integrin expression are reduced as well as adhesion and migration to fibronectin in Myo1f knockdown mast cells. (A) Flow cytometry analysis of $\beta 1$ (CD29) expression on NT and Myo1f shRNA LAD2 cells, (B) $\beta 7$ integrin expression in NT shRNA and Myo1f shRNA. NT shRNA is represented by an empty black curve and Myo1f shRNA is represented by a filled gray curve. The mean of each group is represented in parentheses. (C) NT shRNA cells and Myo1f shRNA LAD2 cells were assayed for adhesion in fibronectin-coated wells, stimulated with SCF (100 ng/mL) for $30 \mathrm{~min}$, and the percentage of adhesion was determined. (D) NT shRNA and Myo1f shRNA LAD2 mast cells were assessed for migration for $4 \mathrm{~h}$ in fibronectin-coated Transwell chambers and then counted under optic microscopy. Viability was tested in the upper wells after the assay. The student's $t$-test $(\mathbf{A}, \mathbf{B})$ or ordinary one-way ANOVA test $(\mathbf{C}, \mathbf{D})$ was used for the statistical analysis $\left({ }^{*} p<0.05,{ }^{* *} p<0.01\right)$. The bar chart data correspond to the mean of at least three independent experiments.

the presence of the kinase inhibitor sunitinib, that causes both molecules to distribute mostly in the cytoplasm. Overall, we concluded that Myolf links 3BP2 to actin cytoskeleton after KIT stimulation.
Myolf has been reported as key for neutrophil migration. Indeed, Myolf knockout mice showed increased susceptibility to infection by Listeria monocytogenes due to an improper neutrophil migration to the infection sites (14). The authors 

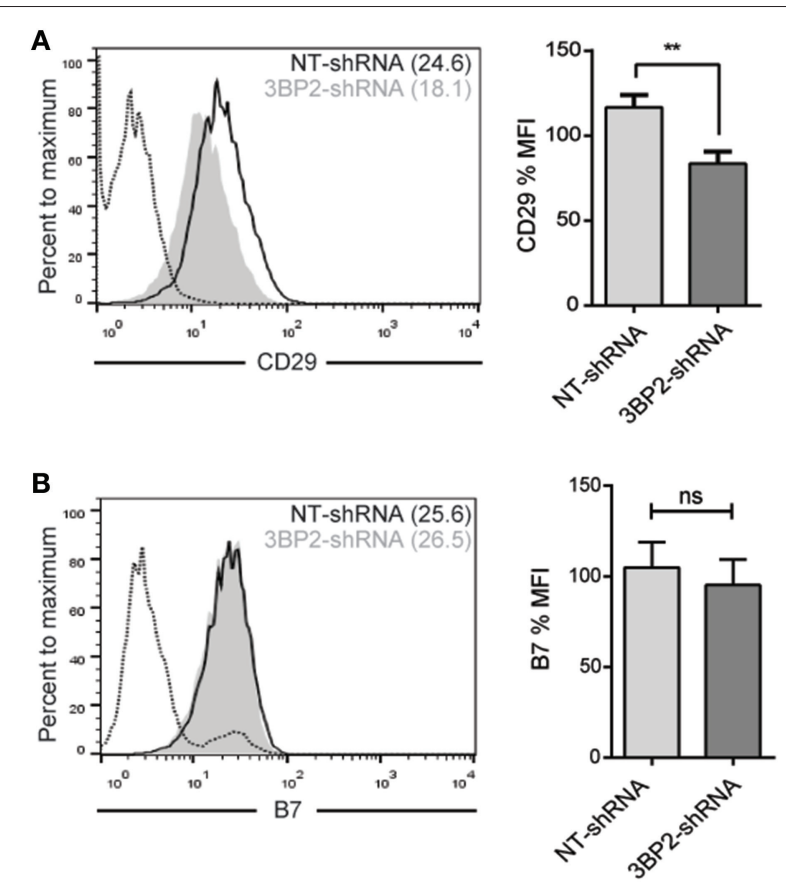

C

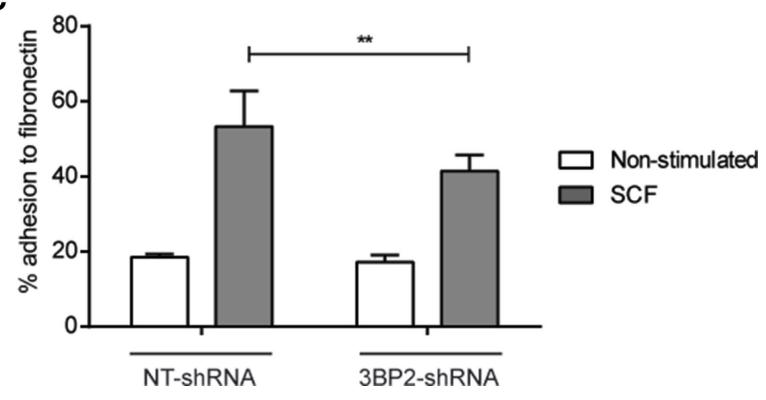

FIGURE 9 | 3BP2 silencing decreases $\beta 1$ expression and significantly impairs adhesion to fibronectin. (A) Flow cytometry analysis of $\beta 1$ (CD29) expression on NT and 3BP2 shRNA LAD2 cells, (B) $\beta 7$ integrin expression in NT shRNA and $3 B P 2$ shRNA. NT shRNA is represented by an empty black curve and $3 \mathrm{BP} 2$ shRNA is represented by a filled gray curve. The mean of each group is represented in parentheses. (C) NT shRNA cells and 3BP2 shRNA LAD2 cells were assayed for adhesion in fibronectin-coated wells, stimulated with SCF (100 ng/mL) for $30 \mathrm{~min}$, and the percentage of adhesion was determined. The student's t-test $\mathbf{( A , B )}$ or ordinary one-way ANOVA test $\mathbf{( C )}$ was used for the statistical analysis $\left({ }^{\star \star} p<0.01\right)$. The bar chart data correspond to the mean of at least three independent experiments.

reported that Myolf prevents excessive exocytosis of $\beta 2$ integrin-containing vesicles by regulating cortical F-actin or by controlling the final step of exocytosis (14). This type of integrin is dominant in integrin-mediated adhesion to the vascular endothelium, a process that is crucial for neutrophil migration to infected tissues $(42,43)$. Lately, Salvermoser and collaborators demonstrated that Myolf is crucial for the dynamics of the deformation of the neutrophil nucleus and consequent capacity of these cells to extravasate in vivo rather than for integrin regulation (44). More recently, it has been shown that Myo1f regulates integrin- $\alpha \mathrm{V} \beta 3$ inducing M1-polarization in macrophages through PI3K/Akt/STAT signaling (45).
In our study, we explore the expression of several integrins after Myolf knockdown. Our data showed that Myolf knockdown decrease the cell surface expression of two integrin $\beta$ chains, $\beta 1$ (CD29) and $\beta 7$, which are critical for mast cell adhesion and migration, usually coupled with the $\alpha 4$ chain. It has also been determined that Fyn kinase plays a role in mediating $\mathrm{KIT} / \beta 1$ integrin crosstalk in mast cells through Rac activation to promote spreading, cytoskeletal remodeling and migration $(39,40)$. Integrin $\alpha-4 / \beta-1$ (VLA- 4$)$ and $\alpha-4 / \beta-7$ are receptors for fibronectin (46). Consequently, we found that Myolf-silenced cells have significantly reduced mast cell adhesion to fibronectin upon SCF activation. Moreover, migration of Myolf-silenced mast cells was impaired, specifically on the integrin ligand (fibronectin)-coated surface, which resembles the physiological environment. Our results suggest that Myolf may regulate integrin trafficking in mast cells and thus possibly affects integrin-vesicle exocytosis. Interestingly, we found that 3BP2 can also regulate $\beta 1$ expression, thus indicating that both molecules are involved in that pathway, but cannot regulate $\beta 7$ integrins, thereby showing a selective cascade for both molecules. $\beta 2$ integrin levels in LAD2 were almost undetectable (data not shown), in line with the very low levels of $\beta 2$ previously reported in human mast cells (47). We cannot discard that Myolf may be acting in the integrin functionality as well. Integrins and actin are coupled through a physical linkage, which provides traction for migration (48). In that context, Myolf would provide a link with the actin cytoskeleton and the adaptor protein 3BP2 delivering signals for adhesion to fibronectin and further cell migration. More experiments are needed to define the mechanism.

With respect to the role of Myolf in the immune system, the Myolf gene has been found to be fused to the mixed lineage leukemia (MLL) gene in acute monocytic leukemia (49). The presence of the Vav1-Myolf fusion protein (where the C-terminal SH3 domain of Vav1 is replaced by the $\mathrm{SH} 3$ of Myo1f) was recently reported in peripheral T-cell lymphomas (PTLC), a heterogeneous group of non-Hodgkin lymphomas frequently associated with poor prognosis. This supports a possible role for the Myolf $\mathrm{SH} 3$ domain in promoting the activity of the Vav1-Myolf oncoprotein (50, 51). Furthermore, Myolf has been proposed as a candidate gene for nonsyndromic deafness (52).

In summary, we have defined a key role for 3BP2 in SCFdependent mast cell migration and identified a new partner, Myolf, which links the adaptor to the actin cytoskeleton following KIT activation. This myosin regulates integrindependent adhesion and migration.

Further investigation is needed to clarify the mechanisms of Myolf in the regulation of migration. The targeting of Myolf could serve as a tool to help shed light on cytoskeleton changes to modulate mast cell function.

\section{AUTHOR CONTRIBUTIONS}

MM conceived the experiments, provided secure funding, wrote, and reviewed the manuscript. AN-F performed, conceived 
experiments, and reviewed the manuscript. EA-E performed experiments and reviewed the manuscript. ES-C provided technical support and reviewed the manuscript. JS conceived experiments and reviewed the manuscript.

\section{ACKNOWLEDGMENTS}

This study has been funded by Instituto de Salud Carlos III (Spain) through the project SAF2015-68124-R (Ministry for Economy and Competitiveness, Spain) co-funded by European Regional Development Fund/European Social Fund Investing in your future and Thematic Networks and Co-operative Research Centers: ARADyAL RD16/0006/0007. AN-F was

\section{REFERENCES}

1. Halova I, Draberova L, Draber P. Mast cell chemotaxis chemoattractants and signaling pathways. Front Immunol. (2012) 3:119. doi: 10.3389/fimmu.2012.00119

2. Kim MS, Radinger M, Gilfillan AM. The multiple roles of phosphoinositide 3-kinase in mast cell biology. Trends Immunol. (2008) 29:493-501. doi: 10.1016/j.it.2008.07.004

3. Draber P, Halova I, Polakovicova I, Kawakami T. Signal transduction and chemotaxis in mast cells. Eur J Pharmacol. (2016) 778:11-23. doi: 10.1016/j.ejphar.2015.02.057

4. Ren R, Mayer BJ, Cicchetti P, Baltimore D. Identification of a tenamino acid proline-rich SH3 binding site. Science. (1993) 259:115761. doi: $10.1126 /$ science. 8438166

5. Ainsua-Enrich E, Alvarez-Errico D, Gilfillan AM, Picado C, Sayos J, Rivera $\mathrm{J}$, et al. The adaptor 3BP2 is required for early and late events in FcepsilonRI signaling in human mast cells. J Immunol. (2012) 189:272734. doi: 10.4049/jimmunol.1200380

6. Ainsua-Enrich E, Serrano-Candelas E, Alvarez-Errico D, Picado C, Sayos J, Rivera J, et al. The adaptor $3 \mathrm{BP} 2$ is required for KIT receptor expression and human mast cell survival. J Immunol. (2015) 194:430918. doi: 10.4049/jimmunol.1402887

7. Chen G, Dimitriou I, Milne L, Lang KS, Lang PA, Fine N, et al. The 3BP2 adapter protein is required for chemoattractant-mediated neutrophil activation. J Immunol. (2012) 189:2138-50. doi: 10.4049/jimmunol.1103184

8. Bustelo XR. Vav family exchange factors: an integrated regulatory and functional view. Small GTPases. (2014) 5:9. doi: 10.4161/21541248.2014.973757

9. Ridley AJ. Rho GTPase signalling in cell migration. Curr Opin Cell Biol. (2015) 36:103-12. doi: 10.1016/j.ceb.2015.08.005

10. Jevremovic D, Billadeau DD, Schoon RA, Dick CJ, Leibson PJ. Regulation of NK cell-mediated cytotoxicity by the adaptor protein 3BP2. J Immunol. (2001) 166:7219-28. doi: 10.4049/jimmunol.166.12.7219

11. Krendel M, Mooseker MS. Myosins: tails (and heads) of functional diversity. Physiology. (2005) 20:239-51. doi: 10.1152/physiol.00014.2005

12. Smrz D, Bandara G, Beaven MA, Metcalfe DD, Gilfillan AM. Prevention of F-actin assembly switches the response to SCF from chemotaxis to degranulation in human mast cells. Eur J Immunol. (2013) 43:187382. doi: 10.1002/eji.201243214

13. Bement WM, Hasson T, Wirth JA, Cheney RE, Mooseker MS. Identification and overlapping expression of multiple unconventional myosin genes in vertebrate cell types. Proc Natl Acad Sci USA. (1994) 91:11767. doi: 10.1073/pnas.91.24.11767c

14. Kim SV, Mehal WZ, Dong X, Heinrich V, Pypaert M, Mellman I, et al. Modulation of cell adhesion and motility in the immune system by Myolf. Science. (2006) 314:136-9. doi: 10.1126/science.1131920

15. Kirshenbaum AS, Akin C, Wu Y, Rottem M, Goff JP, Beaven MA, et al. Characterization of novel stem cell factor responsive human mast cell lines LAD 1 and 2 established from a patient with mast cell sarcoma/leukemia; supported by a grant from Fundación Gangoiti Barrera. We are indebted to the service of advanced optical microscopy of the CCIT (University of Barcelona) and to the Cytomics core facility of the Institut d'Investigacions Biomèdiques August $\mathrm{Pi}$ i Sunyer (IDIBAPS) for technical support. We thank Cristina Luque and Anna Gieryng for assistance with experiments.

\section{SUPPLEMENTARY MATERIAL}

The Supplementary Material for this article can be found online at: https://www.frontiersin.org/articles/10.3389/fimmu. 2019.01058/full\#supplementary-material activation following aggregation of FcepsilonRI or FcgammaRI. Leuk Res. (2003) 27:677-82. doi: 10.1016/S0145-2126(02)00343-0

16. Nilsson G, Blom T, Kusche-Gullberg M, Kjellen L, Butterfield JH, Sundstrom $\mathrm{C}$, et al. Phenotypic characterization of the human mast-cell line HMC-1. Scand J Immunol. (1994) 39:489-98. doi: 10.1111/j.1365-3083.1994.tb03404.x

17. Schindelin J, Arganda-Carreras I, Frise E, Kaynig V, Longair M, Pietzsch T, et al. Fiji: an open-source platform for biological-image analysis. Nat Methods. (2012) 9:676-82. doi: 10.1038/nmeth.2019

18. Sayos J, Martin M, Chen A, Simarro M, Howie D, Morra M, et al. Cell surface receptors Ly-9 and CD84 recruit the X-linked lymphoproliferative disease gene product SAP. Blood. (2001) 97:3867-74. doi: 10.1182/blood.V97.12.3867

19. Tumova M, Koffer A, Simicek M, Draberova L, Draber P. The transmembrane adaptor protein NTAL signals to mast cell cytoskeleton via the small GTPase Rho. Eur J Immunol. (2010) 40:3235-45. doi: 10.1002/eji.2010 40403

20. Tkaczyk C, Metcalfe DD, Gilfillan AM. Determination of protein phosphorylation in Fc epsilon RI-activated human mast cells by immunoblot analysis requires protein extraction under denaturing conditions. J Immunol Methods. (2002) 268:239-43. doi: 10.1016/S0022-1759(02)00210-7

21. Saborit-Villarroya I, Del Valle JM, Romero X, Esplugues E, Lauzurica P, Engel $\mathrm{P}$, et al. The adaptor protein 3BP2 binds human CD244 and links this receptor to Vav signaling, ERK activation, and NK cell killing. J Immunol. (2005) 175:4226-35. doi: 10.4049/jimmunol.175.7.4226

22. Alvarez-Errico D, Oliver-Vila I, Ainsua-Enrich E, Gilfillan AM, Picado C, Sayos J, et al. CD84 negatively regulates IgE highaffinity receptor signaling in human mast cells. J Immunol. (2011) 187:5577-86. doi: 10.4049/jimmunol.1101626

23. Wiederschain D, Wee S, Chen L, Loo A, Yang G, Huang A, et al. Single-vector inducible lentiviral RNAi system for oncology target validation. Cell Cycle. (2009). 8:498-504. doi: 10.4161/cc.8.3.7701

24. Kataoka TR, Kumanogoh A, Bandara G, Metcalfe DD, Gilfillan AM. CD72 negatively regulates KIT-mediated responses in human mast cells. J Immunol. (2010) 184:2468-75. doi: 10.4049/jimmunol.0902450

25. Sun J, Pedersen M, Ronnstrand L. The D816V mutation of c-Kit circumvents a requirement for Src family kinases in c-Kit signal transduction. J Biol Chem. (2009) 284:11039-47. doi: 10.1074/jbc.M808058200

26. Kitaura J, Kinoshita T, Matsumoto M, Chung S, Kawakami Y, Leitges M, et al. IgE- and IgE $+\mathrm{Ag}$-mediated mast cell migration in an autocrine/paracrine fashion. Blood. (2005) 105:3222-9. doi: 10.1182/blood-2004-11-4205

27. Hallgren J, Gurish MF. Mast cell progenitor trafficking and maturation. Adv Exp Med Biol. (2011) 716:14-28. doi: 10.1007/978-1-4419-9533-9_2

28. Dastych J, Metcalfe DD. Stem cell factor induces mast cell adhesion to fibronectin. J Immunol. (1994) 152:213-9.

29. Saborit-Villarroya I, Martinez-Barriocanal A, Oliver-Vila I, Engel P, Sayos J, Martin M. The adaptor 3BP2 activates CD244-mediated cytotoxicity in PKC- and SAP-dependent mechanisms. Mol Immunol. (2008) 45:344653. doi: 10.1016/j.molimm.2008.03.021

30. Foucault I, Le Bras S, Charvet C, Moon C, Altman A, Deckert M. The adaptor protein $3 \mathrm{BP} 2$ associates with VAV guanine nucleotide exchange 
factors to regulate NFAT activation by the B-cell antigen receptor. Blood. (2005) 105:1106-13. doi: 10.1182/blood-2003-08-2965

31. Ory S, Gasman S. Rho GTPases and exocytosis: what are the molecular links? Semin Cell Dev Biol. (2011) 22:27-32. doi: 10.1016/j.semcdb.2010. 12.002

32. Hong-Geller E, Holowka D, Siraganian RP, Baird B, Cerione RA. Activated Cdc42/Rac reconstitutes Fcepsilon RI-mediated $\mathrm{Ca} 2+$ mobilization and degranulation in mutant RBL mast cells. Proc Natl Acad Sci USA. (2001) 98:1154-9. doi: 10.1073/pnas.98.3.1154

33. Gu Y, Filippi MD, Cancelas JA, Siefring JE, Williams EP, Jasti AC, et al. Hematopoietic cell regulation by Rac1 and Rac2 guanosine triphosphatases. Science. (2003) 302:445-9. doi: 10.1126/science. 1088485

34. Yang FC, Kapur R, King AJ, Tao W, Kim C, Borneo J, et al. Rac2 stimulates Akt activation affecting $\mathrm{BAD} / \mathrm{Bcl}-\mathrm{XL}$ expression while mediating survival and actin function in primary mast cells. Immunity. (2000) 12:55768. doi: 10.1016/S1074-7613(00)80207-1

35. Baier A, Ndoh VN, Lacy P, Eitzen G. Rac1 and Rac2 control distinct events during antigen-stimulated mast cell exocytosis. J Leukoc Biol. (2014) 95:76374. doi: $10.1189 / \mathrm{jlb} .0513281$

36. Maeno K, Sada K, Kyo S, Miah SM, Kawauchi-Kamata K, Qu X, et al. Adaptor protein $3 \mathrm{BP} 2$ is a potential ligand of Src homology 2 and 3 domains of Lyn protein-tyrosine kinase. J Biol Chem. (2003) 278:2491220. doi: 10.1074/jbc.M301201200

37. Linnekin D, Deberry CS, Mou S. Lyn associates with the juxtamembrane region of c-Kit and is activated by stem cell factor in hematopoietic cell lines and normal progenitor cells. J Biol Chem. (1997) 272:274505. doi: 10.1074/jbc.272.43.27450

38. Timokhina I, Kissel H, Stella G, Besmer P. Kit signaling through PI 3-kinase and Src kinase pathways: an essential role for Racl and JNK activation in mast cell proliferation. EMBO J. (1998) 17:6250-62. doi: 10.1093/emboj/17. 21.6250

39. Samayawardhena LA, Hu J, Stein PL, Craig AW. Fyn kinase acts upstream of Shp2 and p38 mitogen-activated protein kinase to promote chemotaxis of mast cells towards stem cell factor. Cell Signal. (2006) 18:144754. doi: 10.1016/j.cellsig.2005.11.005

40. Samayawardhena LA, Kapur R, Craig AW. Involvement of Fyn kinase in Kit and integrin-mediated Rac activation, cytoskeletal reorganization, and chemotaxis of mast cells. Blood. (2007) 109:3679-86. doi: 10.1182/blood-2006-11-057315

41. Ueda S, Mizuki M, Ikeda H, Tsujimura T, Matsumura I, Nakano K, et al. Critical roles of c-Kit tyrosine residues 567 and 719 in stem cell factor-induced chemotaxis: contribution of src family kinase and PI3kinase on calcium mobilization and cell migration. Blood. (2002) 99:33429. doi: 10.1182/blood.V99.9.3342

42. Anderson DC, Springer TA. Leukocyte adhesion deficiency: an inherited defect in the Mac-1, LFA-1, and p150,95 glycoproteins. Annu Rev Med. (1987) 38:175-94. doi: 10.1146/annurev.me.38.020187.001135
43. Walzog B, Scharffetter-Kochanek K, Gaehtgens P. Impairment of neutrophil emigration in CD18-null mice. Am J Physiol. (1999) 276:G1125-1130. doi: 10.1152/ajpgi.1999.276.5.G1125

44. Salvermoser M, Pick R, Weckbach LT, Zehrer A, Lohr P, Drechsler $\mathrm{M}$, et al. Myosin if is specifically required for neutrophil migration in 3D environments during acute inflammation. Blood. (2018) 131:188798. doi: 10.1182/blood-2017-10-811851

45. Piedra-Quintero ZL, Serrano C, Villegas-Sepulveda N, Maravillas-Montero JL, Romero-Ramirez S, Shibayama M, et al. Myosin $1 \mathrm{~F}$ regulates M1-polarization by stimulating intercellular adhesion in macrophages. Front Immunol. (2018) 9:3118. doi: $10.3389 /$ fimmu. 2018.03118

46. Ruegg C, Postigo AA, Sikorski EE, Butcher EC, Pytela R, Erle DJ. Role of integrin alpha 4 beta $7 /$ alpha 4 beta $P$ in lymphocyte adherence to fibronectin and VCAM-1 and in homotypic cell clustering. J Cell Biol. (1992) 117:17989. doi: 10.1083/jcb.117.1.179

47. Sperr WR, Agis H, Czerwenka K, Klepetko W, Kubista E, Boltz-Nitulescu G, et al. Differential expression of cell surface integrins on human mast cells and human basophils. Ann Hematol. (1992) 65:10-6. doi: 10.1007/BF01715119

48. Vicente-Manzanares M, Choi CK, Horwitz AR. Integrins in cell migration-the actin connection. J Cell Sci. (2009) 122:199-206. doi: 10.1242/jcs.052894

49. Taki T, Akiyama M, Saito S, Ono R, Taniwaki M, Kato Y, et al. The MYO1F, unconventional myosin type $1 \mathrm{~F}$, gene is fused to MLL in infant acute monocytic leukemia with a complex translocation involving chromosomes 7 , 11, 19 and 22. Oncogene. (2005) 24:5191-7. doi: 10.1038/sj.onc.1208711

50. Boddicker RL, Razidlo GL, Dasari S, Zeng Y, Hu G, Knudson RA, et al. Integrated mate-pair and RNA sequencing identifies novel, targetable gene fusions in peripheral T-cell lymphoma. Blood. (2016) 128:123445. doi: 10.1182/blood-2016-03-707141

51. Abate F, Da Silva-Almeida AC, Zairis S, Robles-Valero J, Couronne L, Khiabanian $\mathrm{H}$, et al. Activating mutations and translocations in the guanine exchange factor VAV1 in peripheral T-cell lymphomas. Proc Natl Acad Sci USA. (2017) 114:764-9. doi: 10.1073/pnas.1608839114

52. Chen AH, Stephan DA, Hasson T, Fukushima K, Nelissen CM, Chen AF, et al. MYO1F as a candidate gene for nonsyndromic deafness, DFNB15. Arch Otolaryngol Head Neck Surg. (2001) 127:921-5. doi: 10.1001/archotol.127.8.921

Conflict of Interest Statement: The authors declare that the research was conducted in the absence of any commercial or financial relationships that could be construed as a potential conflict of interest.

Copyright (๑) 2019 Navinés-Ferrer, Ainsua-Enrich, Serrano-Candelas, Sayós and Martin. This is an open-access article distributed under the terms of the Creative Commons Attribution License (CC BY). The use, distribution or reproduction in other forums is permitted, provided the original author(s) and the copyright owner(s) are credited and that the original publication in this journal is cited, in accordance with accepted academic practice. No use, distribution or reproduction is permitted which does not comply with these terms. 